\title{
Frigocyclinone, a Novel Angucyclinone Antibiotic Produced by a Streptomyces griseus Strain from Antarctica ${ }^{\dagger}$
}

\author{
Christina Bruntner, Tatiana Binder, Wasu Pathom-aree, Michael Goodfellow, \\ Alan T. Bull, Olivier Potterat, Carsten Puder, Stefan Hörer, Angela Schmid, \\ Walter Bolek, Klaus Wagner, Gerhard Mihm, Hans-Peter Fiedler
}

Received: February 3, 2005 / Accepted: April 16, 2005

(C) Japan Antibiotics Research Association

\begin{abstract}
A new angucyclinone antibiotic, frigocyclinone, was isolated from Streptomyces griseus strain NTK 97, consisting of a tetrangomycin moiety attached through a $C$-glycosidic linkage with the aminodeoxysugar ossamine. Frigocyclinone showed antibacterial activities against Gram-positive bacteria.
\end{abstract}

Keywords angucyclinone, screening, antibacterial, antibiotic, Streptomyces griseus

In our HPLC-diode array screening program to detect novel secondary metabolites from actinomycetes isolated from extreme habitats, extracts of culture filtrates of strain NTK 97 drew our attention. Strain NTK 97 was isolated from a terrestrial sample from Terra Nova Bay at Edmundson Point, Antarctica and produced a prominent metabolite whose UV-visible spectrum and retention time were compared with those of the more than 770 reference compounds stored in our HPLC-UV-Vis-Database [2]. The UV-visible spectrum of the dominant compound was highly similar to that of urdamycin B produced by Streptomyces fradiae [3], but their retention times differed significantly. The structure of the isolated metabolite was elucidated as a new angucyclinone with a $C$-glycosidic linked ossamine sugar moiety and was named frigocyclinone (1). The structure is shown in Fig. 1.

Strain NTK 97 was examined for a number of key properties known to be of value in streptomycete systematics [4]. The presence of LL-diaminopimelic acid in the peptidoglycan [5] together with its colonial characteristics [6] allowed its assignment to the genus Streptomyces. More detailed taxonomic studies showed that the organism was a bone fide Streptomyces griseus strain as it produced a grey aerial spore mass on oatmeal agar, formed straigth to flexuous chains of smooth-surfaced spores and shared very high $16 \mathrm{~S}$ rRNA gene sequences (99.6 99.7\%) with members of this taxon [7].

Batch fermentations of Streptomyces griseus strain NTK 97 were carried out in 10-liter stirred tank fermenters (New Brunswick). The production medium consisted of glucose $1 \%$, starch $2 \%$, Bacto peptone $0.3 \%$, meat extract (Oxoid) $0.3 \%$, yeast extract (Ohly Kat G, Deutsche Hefewerke) $0.5 \%$, and $\mathrm{CaCO}_{3} 0.3 \%$ in tap water ( $\mathrm{pH} 7.0$ ). The fermentation was conducted at $27^{\circ} \mathrm{C}$ for 118 hours with an aeration rate of $0.5 \mathrm{v} / \mathrm{v} / \mathrm{m}$ and an agitation of $200 \mathrm{rpm}$. The
H.-P. Fiedler (Corresponding author), C. Bruntner, T. Binder: Mikrobiologisches Institut, Universität Tübingen, Auf der Morgenstelle 28, D-72076 Tübingen, Germany, E-mail: hans-peter.fiedler@uni-tuebingen.de

W. Pathom-aree, M. Goodfellow: School of Biology, University of Newcastle, Newcastle upon Tyne NE1 7RU, United Kingdom

A. T. Bull: Research School of Biosciences, University of Kent, Canterbury CT2 7NJ, United Kingdom
O. Potterat, C. Puder, S. Hörer, A. Schmid, W. Bolek, K. Wagner, G. Mihm: Boehringer Ingelheim Pharma GmbH \& Co KG, Birkendorfer Str. 65, D-88397 Biberach, Germany

†Art. No. 33 in 'Biosynthetic Capacities of Actinomycetes'. Art. No. 32: See ref. 1 
production of 1 reached a maximal value of $22 \mathrm{mg} /$ liter after 96 hours and decreased thereafter. Increasing the glucose concentration of the fermentation medium to $30 \mathrm{~g} /$ liter increased the maximum product concentration to $40 \mathrm{mg} /$ liter observed after 120 hours.

The culture filtrate (21 liters) was loaded onto an Amberlite XAD-16 column $(8 \times 45 \mathrm{~cm})$ and $\mathbf{1}$ was eluted by increasing concentrations of $\mathrm{MeOH}$. The $100 \% \mathrm{MeOH}-$ fraction, which contained 1, was concentrated and dried $(1.8 \mathrm{~g})$. The raw product was dissolved in $\mathrm{MeOH}$, dried with addition of $20 \mathrm{~g}$ of silica gel 60 under reduced pressure and was then subjected to adsorption chromatography using a column of silica gel $60(2.5 \times 33$ $\mathrm{cm})$. The separation was accomplished by gradient elution using increasing concentrations of $\mathrm{MeOH}$ in $\mathrm{CH}_{2} \mathrm{Cl}_{2}$. 1 containing fractions were combined and concentrated in vacuo to dryness $(127 \mathrm{mg})$. Final purification of $70 \mathrm{mg}$ of crude 1 on a Sephadex LH-20 column $(2.5 \times 70 \mathrm{~cm})$ with $\mathrm{MeOH}$ afforded $47 \mathrm{mg}$ of pure $\mathbf{1}$.

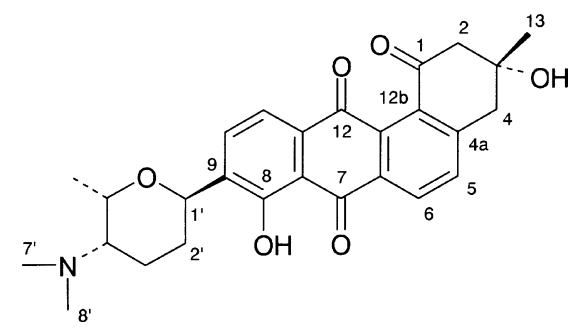

Fig. 1 Structure of frigocyclinone (1).
The UV-spectrum of compound $\mathbf{1}$ was in agreement with a substituted 1,2,3,4-tetrahydro-3-methyl-8-hydroxybenz $[\alpha]$ anthraquinone chromophore with absorption maxima at 269, 322 and $408 \mathrm{~nm}$. The physico-chemical properties of $\mathbf{1}$ are summarized in Table 1. The molecular formula of 1 was determined to be $\mathrm{C}_{27} \mathrm{H}_{29} \mathrm{NO}_{6}$ by the analysis of the ESI-TOF MS spectrum of $\mathbf{1}$ recorded with lockspray $\left[(\mathrm{M}+\mathrm{H})^{+}\right.$: found $\mathrm{m} / \mathrm{z}$ 464.2052; calc 464.2073] as well as the NMR data including DEPT-135. 1D and 2D NMR data (Table 2) confirmed the presence of an angucyclinone ring system and showed this to be identical with tetrangomycin [8]. ${ }^{1} \mathrm{H}$ and ${ }^{13} \mathrm{C}$ chemical shifts were in very good agreement with the data reported [9]. In addition, an aminodeoxysugar was attached through a $C$ -

Table 1 Physico-chemical properties of frigocyclinone (1)

\begin{tabular}{ll}
\hline Appearance & orange-brown solid \\
Molecular weight & 463 \\
Molecular formula & $\mathrm{C}_{27} \mathrm{H}_{29} \mathrm{NO}_{6}$ \\
ESI-TOF MS $(\mathrm{m} / \mathrm{z})$ & \\
Found & $464.2052(\mathrm{M}+\mathrm{H})^{+}$ \\
$\quad$ Calcd & 464.2073 \\
UV $\lambda_{\max }^{\text {EtOH }} \mathrm{nm}(\varepsilon)$ & $269(33300), 322(3300), 408(6400)$ \\
IR (ATR) $v_{\max } \mathrm{cm}^{-1}$ & $3365(\mathrm{br}), 2961,2870,2821,2774$, \\
& $1702,1672,1630,1589,1426$, \\
CD $\lambda_{\text {extreme }}^{\text {MecN }}(\theta) \mathrm{deg} \cdot \mathrm{cm}^{2}$. & $(2700), 355(-200), 325(500)$, \\
decimole & $269(-21100), 218(5000)$ \\
\hline
\end{tabular}

Table $2{ }^{1} \mathrm{H}$ and ${ }^{13} \mathrm{C}$ NMR data of frigocyclinone (1)

\begin{tabular}{|c|c|c|c|c|c|}
\hline No & $\delta_{\mathrm{C}}$ & $\delta_{\mathrm{H}}$ & No & $\delta_{\mathrm{C}}$ & $\delta_{\mathrm{H}}$ \\
\hline 1 & 196.7 & - & $11 a$ & 133.5 & - \\
\hline \multirow[t]{2}{*}{2} & 53.1 & $3.05(d, 14.0)$ & 12 & 182.5 & - \\
\hline & & $2.74(d d, 14.0,1.8)$ & $12 \mathrm{a}$ & 135.5 & - \\
\hline 3 & 71.5 & - & $12 b$ & 135.5 & - \\
\hline \multirow[t]{2}{*}{4} & 43.5 & $3.21(\mathrm{~d}, 17.0)$ & 13 & 29.7 & 1.35 (s) \\
\hline & & $3.07(\mathrm{dd}, 17.0,1.6)$ & $1^{\prime}$ & 63.6 & $4.95_{\mathrm{ax}}(\mathrm{m})$ \\
\hline $4 a$ & 149.3 & - & $2^{\prime}$ & 31.4 & $2.08_{\text {eq }}(m)$ \\
\hline 5 & 134.1 & $7.72(d, 8.0)$ & & & $1.28_{\mathrm{ax}}(\mathrm{m})$ \\
\hline 6 & 128.5 & $8.21(d, 8.0)$ & $3^{\prime}$ & 22.3 & $1.91_{\mathrm{eq}}(\mathrm{m})$ \\
\hline $6 a$ & 132.8 & - & & & $1.61_{\mathrm{ax}}(\mathrm{m})$ \\
\hline 7 & 187.4 & - & $4^{\prime}$ & 63.5 & $2.20_{\mathrm{ax}}(\mathrm{m})$ \\
\hline $7 a$ & 114.6 & - & $5^{\prime}$ & 70.9 & $4.42_{\mathrm{eq}}(\mathrm{m})$ \\
\hline 8 & 157.6 & - & $6^{\prime}$ & 11.5 & $1.24(d, 6.8)$ \\
\hline 9 & 137.7 & - & $7^{\prime}, 8^{\prime}$ & 42.9 & $2.17(\mathrm{~s})$ \\
\hline 10 & 133.4 & $7.85(\mathrm{dd},(7.8,0.5)$ & $3-\mathrm{OH}$ & & $5.01(b r)$ \\
\hline 11 & 118.4 & $7.53(d, 7.8)$ & $8-\mathrm{OH}$ & & $12.1(\mathrm{~s}, \mathrm{br})$ \\
\hline
\end{tabular}

$\delta$ from TMS in DMSO- $d_{6} ; J$ in $\mathrm{Hz}$ 
Table 3 Minimal inhibition concentrations $(\mu \mathrm{M})$ of frigocyclinone (1), urdamycin $\mathrm{B}$, erythromycin and vancomycin

\begin{tabular}{lcccc}
\hline \multicolumn{1}{c}{ Test organism } & $\mathbf{1}$ & Urdamycin B & Erythromycin & Vancomycin \\
\hline Bacillus subtilis DSM 10 & 10 & 100 & 1 & 0.33 \\
Staphylococcus aureus DSM 20231 & 33 & $>100$ & 1 & 1 \\
\hline
\end{tabular}

glycosidic linkage at C-9, which was confirmed by the $\mathrm{HC}$ long-range couplings between carbon C-9 and the protons $\mathrm{H}-1^{\prime}$ and $\mathrm{H}-2^{\prime}$ ax of the tetrahydropyran moiety in the HCHMBC spectrum. The sugar was identified as ossamine by detailed 1D- and 2D-NMR analysis. The tetrahydropyran spin systems could be identified from the HH-COSY spectrum. The assignment of the stereochemistry at carbon atoms $\mathrm{C}-1^{\prime}, \mathrm{C}-4^{\prime}$ and $\mathrm{C}-5^{\prime}$ was assigned by the intense ROESY cross peaks between the low-field proton $\mathrm{H}-1^{\prime}$ (ax, $\delta=4.95 \mathrm{ppm})$ and proton $\mathrm{H}-3^{\prime}(\mathrm{ax}, \delta=1.61 \mathrm{ppm})$ as well as to the methyl protons $\mathrm{H}-6^{\prime}$ (ax, $\delta=1.24 \mathrm{ppm}$ ) positioning these protons on the same site of the tetrahydropyran ring, whereas the strong ROESY effects between $\mathrm{H}-2^{\prime}$ (ax, $\delta=1.28 \mathrm{ppm}$ ) and $\mathrm{H}-4^{\prime}(\mathrm{ax}, \delta=2.20 \mathrm{ppm})$ describe their close spatial neighborhood on the other site of the sugar ring. Comparison with the NMR data reported for ossamine [10] and its stereoisomer forosamine [11], where both methyl and $N, N$-dimethyl substituents are in an equatorial orientation, confirmed the identification of the sugar moiety. The relative configuration at $\mathrm{C}-3$ was established by an X-ray diffraction analysis, which at the same time confirmed the complete structure obtained from NMR data. Crystals were grown from a mixture of acetone and $n$-hexane. Crystal data were as follows: monoclinic, $a=25.94(1) \AA, b=7,306(2) \AA, c=12,745(5) \AA, \beta=89,97(3)^{\circ}$, $Z=4$, spacegroup $P 2_{1}$. A total of 4944 reflections were measured by a Rigaku AFC7R diffractometer with graphite monochromated $\mathrm{Cu}-\mathrm{K} \alpha$-radiation $(\lambda=1.54178 \AA)$ using a yellow prismatic crystal, $0.15 \times 0.15 \times 0.1 \mathrm{~mm}$ at $100 \mathrm{~K}$. The crystal structure was solved by direct methods with the program SHELXS86 [12], and refined by full-matrix least squares. Non-hydrogen atoms were refined with anisotropic temperature factors, and hydrogen atoms were included and not refined. The final $R$ and $R w$ for 2725 reflections with $I>2 s(I)$ were 0.064 and 0.078 , respectively. The maximum and minimum peaks on the final difference fourier map were $0.28 e^{-} / \AA^{-3}$ and $-0.44 e^{-} / \AA^{-3}$, respectively. The absolute configuration was not established. However, $3 R$, $1^{\prime} R, 4^{\prime} S, 5^{\prime} S$ configuration can be postulated, since only $R$ configuration at $\mathrm{C}-3$ is known in naturally occurring angucyclinones. The molecular structure of $\mathbf{1}$ is depicted in Fig 2.

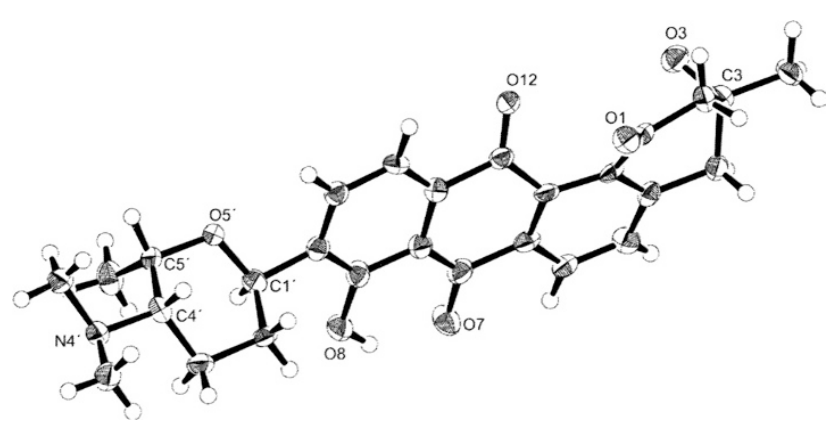

Fig. 2 Molecular structure of frigocyclinone (1) using ORTEP.

The antimicrobial spectrum of $\mathbf{1}$ was determined by agar plate diffusion assays and $\mathbf{1}$ revealed good inhibitory activity against Gram-positive bacteria, whereas Gramnegative bacteria like Escherichia coli, Pseudomonas fluorescens and Proteus mirabilis were not sensitive. Inhibitory activity of $\mathbf{1}$ was not detected against filamentous fungi like Botrytis cinerea, Aspergillus viridinutans, Penicillium notatum and Paecilomyces variotii. Yeasts such as Saccharomyces cerevisiae and Candida albicans were also insensitive to $\mathbf{1}$. The minimal inhibition concentration of $\mathbf{1}$ was significantly higher in comparision to vancomycin and erythromycin, but 1 revealed more potent activity than urdamycin B (Table 3).

Acknowledgements W. P.-a. is grateful to the DPST program and the Royal Thai Government for financial support. Thanks are due to Mrs. P. Breh, N. Jakob and Mrs. A. Peic (Boehringer Ingelheim Pharma GmbH \& Co. KG, Biberach, Germany), and Mr. C. Tanzer and Mr. G. Grewe (University of Tübingen) for technical assistance. We thank the late David Wynn-Williams for the gift of Antarctic samples, Mrs. Dr. M. Bauer (Boehringer Ingelheim Pharma) for recording the $\mathrm{CD}$ spectrum, and Agilent Technologies Germany for HPLC software support.

\section{References}

1. Antal N, Fiedler HP, Stackebrandt E, Beil W, Ströch K, Zeeck A. Retymicin, galtamycin B, saquayamycin $\mathrm{Z}$ and ribofuranosyllumichrome, novel secondary metabolites from 
Micromonospora sp. Tü 6368. I. Taxonomy, fermentation, isolation and biological activities. J Antibiot 58: 95-102 (2005)

2. Fiedler HP. Biosynthetic capacities of actinomycetes. 1. Screening of secondary metabolites by HPLC and UVvisible absorbance spectral libraries. Nat Prod Lett 2: 119-128 (1993)

3. Drautz H, Zähner H, Rohr J, Zeeck A. Metabolic products of microorganisms. 234. Urdamycins, new angucycline antibiotics from Streptomyces fradiae. I. Isolation, characterization and biological properties. J Antibiot 49: 1657-1669 (1986)

4. Manfio GP, Zakrzewska-Czerwinska J, Atalan E, Goodfellow M. Towards minimal standards for the description of Streptomyces species. Biotekhnologiya 8: 228-237 (1995)

5. Staneck JL, Roberts GD. Simplified approach to the identification of aerobic actinomycetes by thin-layer chromatography. Appl Microbiol 28: 226-231 (1974)

6. Williams ST, Goodfellow M, Alderson G. Genus Streptomyces Waksman and Henrici 1943, 339 ${ }^{\mathrm{AL}}$. In Bergey's Manual of Systematic Bacteriology. Volume 4. Ed., Williams ST et al., pp. 2452-2492, Williams \& Wilkins, Baltimore (1989)

7. Liu Z, Shi Y, Zhang Y, Zhou Z, Lu Z, Li W, Rodriguez C,
Goodfellow M. Classification of Streptomyces griseus (Krainsky 1914) Waksman and Henrici 1948 and related species and the transfer of 'Microtetraspora cinerea' to the genus Streptomyces as Streptomyces yanii sp. nov. Int J Syst Evol Microbiol, in press (2005)

8. Dann M, Lefemine DV, Barbatschi F, Shu P, Kunstmann MP, Mitscher LA, Bohonos N. Tetrangomycin, a new quinone antibiotic. Antimicrob Agents Chemother 1965: 832-835 (1965)

9. Rohr J, Zeeck A. Metabolic products of microorganisms. 240. Urdamycins, new angucyline antibiotics from Streptomyces fradiae. II. Structural studies of urdamycins B to F. J Antibiot 40: 459-467 (1987)

10. Hochlowski JE, Mullally MM, Brill GM, Whittern DN, Buko AM, Hill P, McAlpine JB. Dunaimycins, a new complex of spiroketal 24-membered macrolides with immunosuppressive activity. II. Isolation and elucidation of structures. J Antibiot 44: 1318-1330 (1991)

11. Alam P, Barber J, Brennan RJ, Kennedy K, Tehrani MHH. ${ }^{1} \mathrm{H}$ and ${ }^{13} \mathrm{C}$ NMR spectra of spiramycin I in organic and aqueous solutions. Magn Reson Chem. 33: 228-231 (1995)

12. Sheldrick GM. SHELXS86. In Crystallographic Computing 3. Ed., Sheldrick GM et al., pp. 175-189, Oxford University Press (1985) 